\title{
Tuning porosity via control of interpenetration in a zinc isonicotinate metal organic framework
}

\author{
SHYAMAPADA NANDI and RAMANATHAN VAIDHYANATHAN* \\ Department of Chemistry, Indian Institute of Science Education and Research, Pune 411008, India \\ e-mail: vaidhya@iiserpune.ac.in
}

MS received 17 April 2014; revised 23 May 2014; accepted 6 June 2014

\begin{abstract}
Metal organic frameworks (MOFs) are a class of porous solids formed by linking metal centres or metal clusters by suitable organic ligands capable of generating porosity in the microporous and mesoporous regimes. They have been investigated extensively for their gas storage applications in the last two decades. Interpenetration is nature's way of avoiding excessive free-space within the large porous networks by growing identical but independent networks within a parent network to decrease the solvent accessible voids and increase stability. A major challenge in MOF synthesis involves minimizing or completely eliminating the extent. In this paper, we report a zinc isonicotinate (or pyridyl-4-carboxylate, 4-PyC) MOF, 1, prepared by tuning the synthesis conditions to minimize interpenetration. The three-fold interpenetration presented in this material is unusual and has been compared to the other zinc isonicotinates to identify the differences contributing to the improved porosity. In addition, the thermal decomposition of $\mathbf{1}$ in an oxygen-deficient medium has been shown to yield significantly porous carbon embedded with $\mathrm{ZnO}$ nanoparticles.
\end{abstract}

Keywords. Metal organic framework; zinc; isonicotinate; unusual three-fold interpenetration; postcombustion porosity.

\section{Introduction}

Owing to their crystalline nature and unprecedented porosities or surface areas, metal organic frameworks have found space in a wide range of material applications. ${ }^{1}$ They have been widely explored for gas storage, separation, sensing and more. ${ }^{2}$ Several organic linkers of varying sizes, shapes and functionalities have been employed for the synthesis of MOFs. ${ }^{3}$ However, most attempts to prop open the frameworks for higher porosity or larger voids have resulted in 'interpenetration'. ${ }^{4}$ A natural phenomenon wherein an identical, but cyrstallographically independent network grows within the parent framework without forming any actual chemical bond with the parent framework. Depending on the symmetry of the parent network, there can be interpenetrations ranging from two to ten folds. ${ }^{4}$ While the higher folds generally render the frameworks more stable, they also partially or completely diminish the solvent accessible voids within the framework. When porosity is to serve as a function, this undesirable interpenetration needs to be avoided. In general, the shorter the organic spacer, lower are the chances of interpenetration. Surprisingly, even short organic spacers such as oxalate and cyanides tend

\footnotetext{
*For correspondence
}

to form interpenetrated networks. ${ }^{4-6}$ From a material standpoint, our focus has been to control the interpenetration in isonicotinate frameworks using some of the existing knowledge and our synthetic expertise. We carried out a systematic study of the zinc isonicotinate frameworks which seem to have high propensity towards forming interpenetrated frameworks.

Recently, there has been interest in using metal organic frameworks as single-source precursors to generate homogeneous metal or metal oxide nano particle dispersed carbons via oxygen-deficient combustion routes. ${ }^{7-9}$ In this paper we report a three-fold interpenetrated zinc iso-nicotinate $\mathrm{MOF}, \mathrm{Zn}_{2}(\mathrm{OOC}$ $\left.\mathrm{C}_{5} \mathrm{H}_{4} \mathrm{~N}\right)_{4}(\mathrm{DMF}), \mathbf{1}$, which exhibits an unusual interpenetration resulting in much more porosity compared to a closely related zinc isonicotinate MOF, $\mathbf{2}$, with symmetrical three-fold interpenetration. ${ }^{10}$ Also, the postcombustion product of $\mathbf{1}$ has been compared to that of the denser zinc isonicotinates for their porosity.

\section{Experimental}

\subsection{Synthesis}

Zinc isonicotinates have been reported with a three-fold interpenetrated structure ${ }^{10}$ and an non-interpenetrated structure. ${ }^{11}$ While the former has been synthesized via 
a solvothermal synthesis involving an in situ ligand formation, the latter has been prepared using a simple layering technique at low temperature $\left(\sim 4^{\circ} \mathrm{C}\right) .{ }^{11}$ Our attempts to reproduce the low temperature non-interpenetrated phase have so far been unsuccessful. The low temperature route yielding a noninterpenetrated phase is in agreement with the general understanding that interpenetration is favoured at higher temperatures. $^{12,13}$ Detailed investigations have been carried out to tune the interpenetration in crystalline frameworks and many synthetic approaches involving the parameters such as temperature, dilution, $\mathrm{pH}$ during the synthesis have been presented for the control of interpenetration. ${ }^{12 a}$ Following this, we applied several variations to our synthesis involving the zinc and isonicotinic acid (table S1). 1 was synthesized by reacting $0.109 \mathrm{~g}$ of zinc acetate tetrahydrate $(0.5 \mathrm{mmol})$ with $0.122 \mathrm{~g}$ of isonicotinic acid $(1 \mathrm{mmol}$, prepared by hydrolysis of 4-cyanopyridine by refluxing in $12 \mathrm{M}$ $\mathrm{HCL}$ for $12 \mathrm{~h})$ and $0.06 \mathrm{~g}$ nicotinic acid $(0.5 \mathrm{mmol})$ in a solution containing $3 \mathrm{~mL}$ of $\mathrm{DMF}+2 \mathrm{~mL}$ of $\mathrm{MeOH}$ using solvothermal conditions. Contents were sealed in a $23 \mathrm{~mL}$ Teflon liner and heated at $85^{\circ} \mathrm{C}$ for $72 \mathrm{~h}$. The product was a crop of small colourless prismatic crystals which were isolated by a vacuum filtration and dried under ambient condition. Yield: $0.2 \mathrm{~g}, 58 \%$ (M.Wt. of $\left.\mathrm{Zn}_{2}\left(\mathrm{OOC}-\mathrm{C}_{5} \mathrm{H}_{4} \mathrm{~N}\right)_{4}(\mathrm{DMF})=692.3 \mathrm{gmol}^{-1}\right)$. EDAX-CHN analysis (calc. within brackets): $\mathrm{Zn}=19.8$ (18.9\%); $\mathrm{C}=47.2$ (46.9\%); $\mathrm{O}=20.3$ (20.8\%); $\mathrm{N}=$ $10.9(10.12 \%)$. Bulk purity was confirmed from a characteristic powder XRD which matched well with the PXRD simulated from the single crystal structure (figure 1). In figure 1 there are some minor peak shifts noticed in the PXRD (example peak at $2 \theta=\sim 15^{\circ}$ ) and this can be attributed to the changes caused by occluded solvents. Note: The presence of nicotinic acid

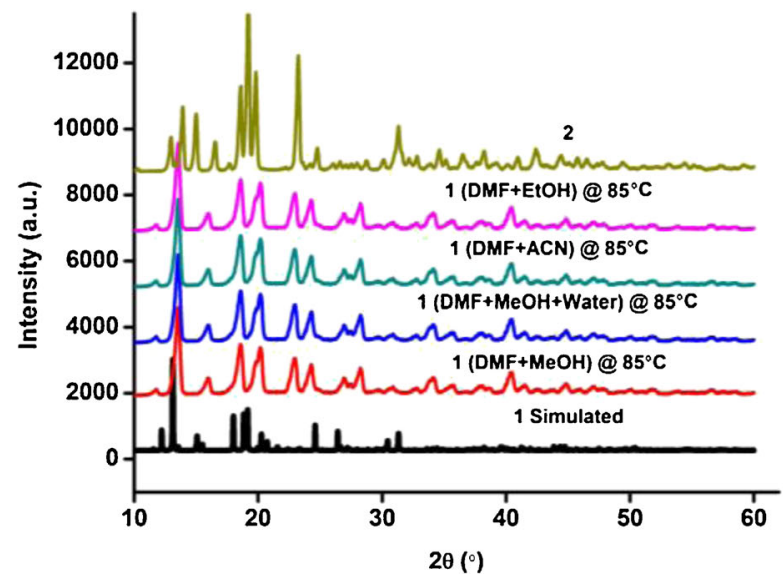

and maintaining the synthesis temperature to be below $85^{\circ} \mathrm{C}$ seem to be extremely crucial to obtaining phase $\mathbf{1}$ (table S1). Synthesis conditions for $\mathbf{2}$ is presented in table $\mathrm{S} 1$.

\subsection{Single crystal data collection}

Single crystals were mounted by freezing to the tip of a glass loop using Paratone oil. Experiments were conducted at $173 \mathrm{~K}$ on a Bruker SMART APEX fourcircle diffractometer with a micro-focus $\mathrm{Cu} \mathrm{K}-\alpha$ radiation $(\lambda=1.5418 \AA)$ and equipped with a PHOTON100 CMOS detector. The intensity data collection was performed in the scanning mode with the goniometer and detector angular settings optimized using the program COSMOS. The unit cell and the orientation matrix were refined using the entire data set of reflections. The diffraction spots were measured in full with a high accuracy, scaled, corrected for Lorentzpolarization correction, and integrated using Bruker SAINT (1997). Absorption effects were empirically corrected by using multi-scan, SADABS (Sheldrick, G. M., SADABS; Universitat Gottingen, 1997). Structure was solved using Direct methods (SHELXS-97). Full-matrix least-squares refinement on $\mathrm{F}^{2}$ was carried out using SHELXTL suite of programs. The crystallographic data and conditions for structure analysis are given below. Sufficient high angle reflections could not be achieved due to extremely small size of the crystal $(0.05 \mathrm{~mm} \times 0.02 \mathrm{~mm} \times 0.02 \mathrm{~mm})$. This resulted in a completion of $\sim 94 \%$. However the entire framework atoms could be solved and refined anisotropically without any NPDs. All the hydrogens were fixed by placing them in a riding mode. Solvent molecules could not be identified or modelled satisfactorily from the difference

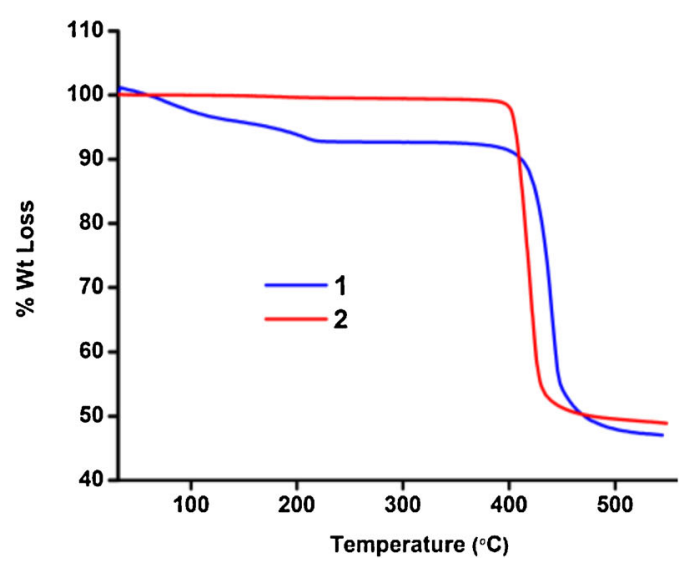

Figure 1. Left: Comparison of the PXRD patterns of 1 synthesized under different conditions and that of 2. Right: Comparison of the TGAs of $\mathbf{1}$ and 2. Note that unlike 2, $\mathbf{1}$ shows clear loss of solvents (MeOH+DMF). 
Fourier map, hence a detailed SQUEEZE routine was performed using PLATON.

Crystallographic data for $\mathbf{1}: \mathrm{Zn}_{2}\left(\mathrm{OOC}-\mathrm{C}_{5} \mathrm{H}_{4} \mathrm{~N}\right)_{4}(\mathrm{DMF})$, $\mathrm{M}_{w}=692.28$, Monoclinic, $\mathrm{Cc}, \mathrm{a}=19.6177(27), \mathrm{b}=$ $18.5682(26), \mathrm{c}=14.6420(21) \AA, \beta=128.717(7)^{\circ}$, $\mathrm{V}=4161.69(10) \AA^{3}, \mathrm{Z}=8, \lambda=1.5418 \AA, \mathrm{T}=$ $173(2) \mathrm{K}, \mathrm{R}_{1}(\mathrm{obs})=0.062, \mathrm{Rw}(\mathrm{obs})=0.1246 ; \mathrm{GOF}=$ 1.007. CIF file is available free of charge from the Cambridge Crystallographic Database with reference numbers CCDC 998824 via www.ccdc.cam.ac.uk/data request/cif.

\subsection{Other characterizations}

Details of powder x-ray, TGA, IR, UV, EDAX and FESEM are presented in the supporting information.

\section{Results and Discussion}

Structure of $\mathbf{1}$ is made up of the linkages between tetrahedrally co-ordinated $\mathrm{Zn}$ centres. Each $\mathrm{Zn}$ centre is connected to two different 4-PyC units via monodentately linking carboxylate units and $\mathrm{N}$-atoms of two different pyridyl groups (figure 2a). Each of the tetrahedral $\mathrm{Zn}$ nodes connects to four other similar tetrahedral nodes giving rise to a building unit which resembles the adamantane (figure $2 b$ ). The connectivity among the adamantane units via the 4-PyC units result in a diamondoid network with large pores running along the a-, b- and c-axes (figures $2 \mathrm{~b}$ and $\mathrm{S} 1$ ). Such large pores facilitate a three-fold interpenetration within them (figure 3). This reduces the channel dimensions, and thereby the accessible voids quite considerably.
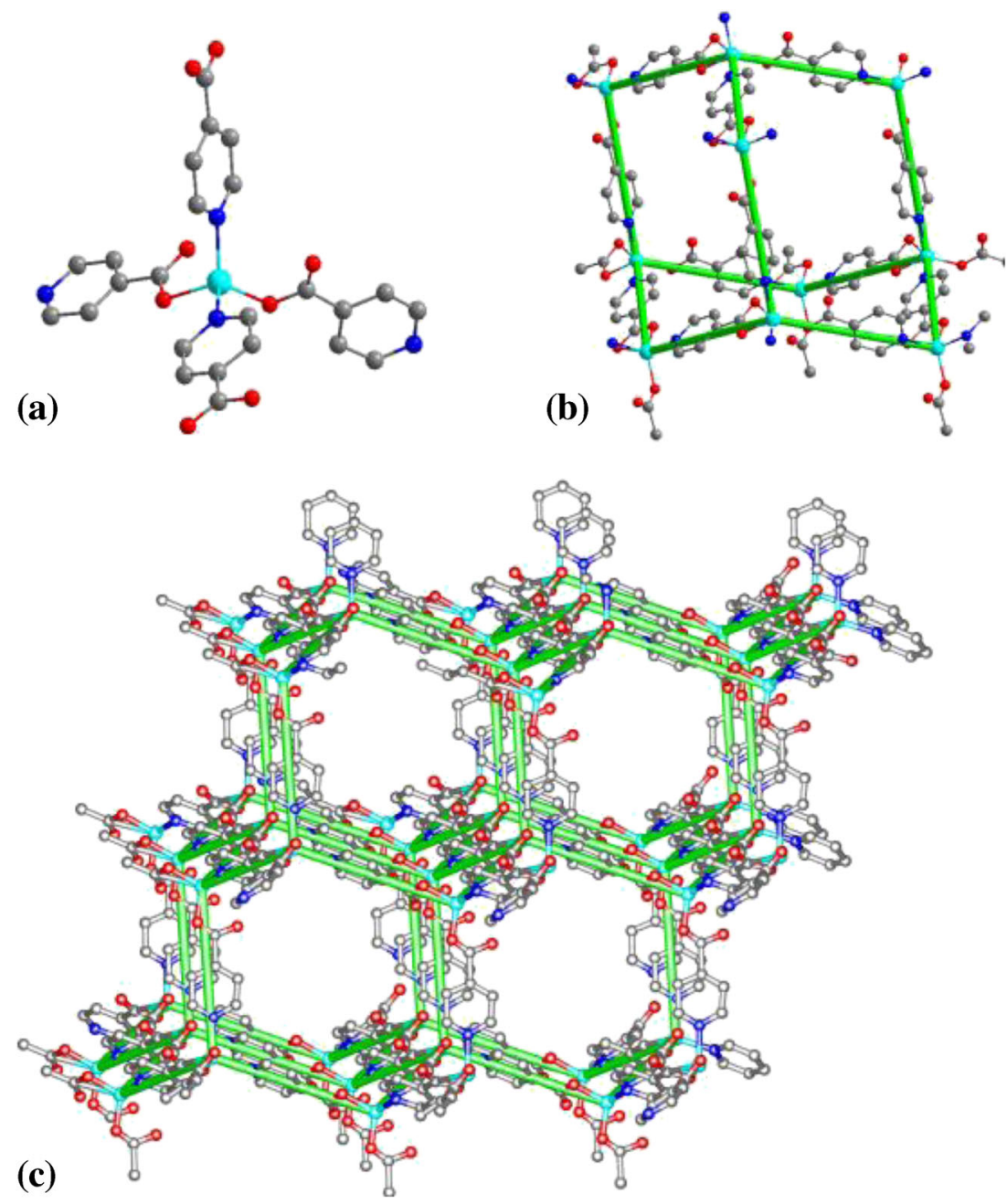

Figure 2. (a) The tetrahedral Zinc centre in $\mathbf{1}, \mathrm{Zn}-\mathrm{O}=1.9702(2)$ and $1.9748(3) ; \mathrm{Zn}-\mathrm{N}=2.0097(2)$ and 2.0389(2) $\AA, \mathrm{N}-\mathrm{Zn}-\mathrm{O}=120.338(2)$; $\mathrm{N}-\mathrm{Zn}-\mathrm{N}=103.249(8) ; \mathrm{N}-\mathrm{Zn}-\mathrm{O}=110.097(9) ; \mathrm{O}-\mathrm{Zn}-\mathrm{O}=113.337(10)^{\circ}$. (b) The adamantane like unit which forms the basic building unit of $\mathbf{1}$. (c) The three-dimensional diamondoid network of 1. Colour code: Cyan $=\mathrm{Zn}$; Red $=\mathrm{O}$; Blue $=\mathrm{N}$; Grey $=\mathrm{C}$ and the green lines indicate the diamondoid network. Note the interpenetration is not represented in these figures for clarity. See figure $\mathrm{S} 1$ for channel dimensions. 


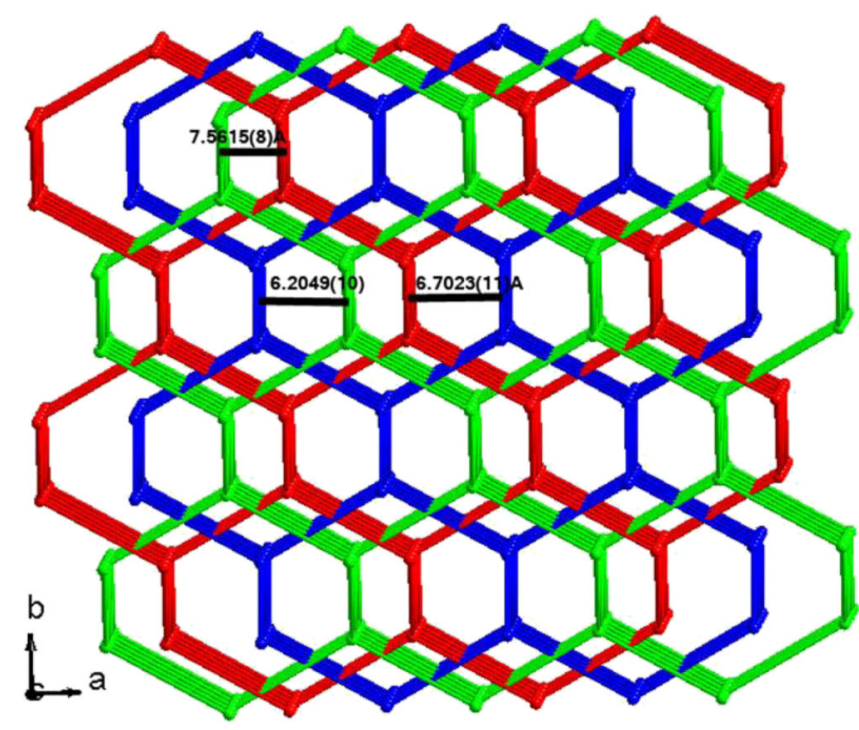

Figure 3. The three-fold interpenetration in 1. Note that the networks are shifted from each other by different units. Also, the blue and green networks are significantly displaced from the centroid of the parent red network.

A SQUEEZE analysis performed using PLATON indicated the potential solvent accessible void of $\sim 18.5 \%$, which was encouraging. ${ }^{14}$ A thermogravimetric analysis done on the as-made phase of $\mathbf{1}$ showed a solvent weight loss of about $9.5 \%$ in the range of 100 to $180^{\circ} \mathrm{C}$, which corresponds to the loss of DMF molecules (calc: $10.5 \%$, figure 1). 1 was found to be stable to the loss of these DMF molecules. The framework decomposition starts only above $400^{\circ} \mathrm{C}$, which signifies exceptional thermal stability. Encouraged by the squeeze and the TGA findings, we activated the sample by soaking it in acetone over $12 \mathrm{~h}$, followed by evacuation at $180^{\circ} \mathrm{C}$ for $12 \mathrm{~h}$.

1 did not adsorb any $\mathrm{N}_{2}$ at $77 \mathrm{~K} . \mathrm{CO}_{2}$ adsorption on 1 was carried out at 273 and $298 \mathrm{~K}$, where an uptake of 2.8 and $1.6 \mathrm{mmol} / \mathrm{g}$ were observed (figure 4 ).

Our initial attempts to combine $\mathrm{Zn}$ and isonicotinate in a MOF resulted in a known phase which also is a three-fold interpenetrated one, 2. ${ }^{10}$ And this seemed to be quite a stable phase corresponding possibly to a significantly large energy minimum (table S1). The three-fold interpenetration in this phase generates a dense framework which does not seem to have any solvent accessible voids as evidenced from the TGA (figure 1). The key identification was that $\mathbf{1}$ was the most probable phase when the synthesis was carried out under different solvothermal conditions but below $85^{\circ} \mathrm{C}$ (figure 1) and in the presence of pyridyl-3-carboxylic acid a.k.a. nicotinic acid, on the other hand, 2 seems to be the favoured at temperatures above $85^{\circ} \mathrm{C}$ (table S1).

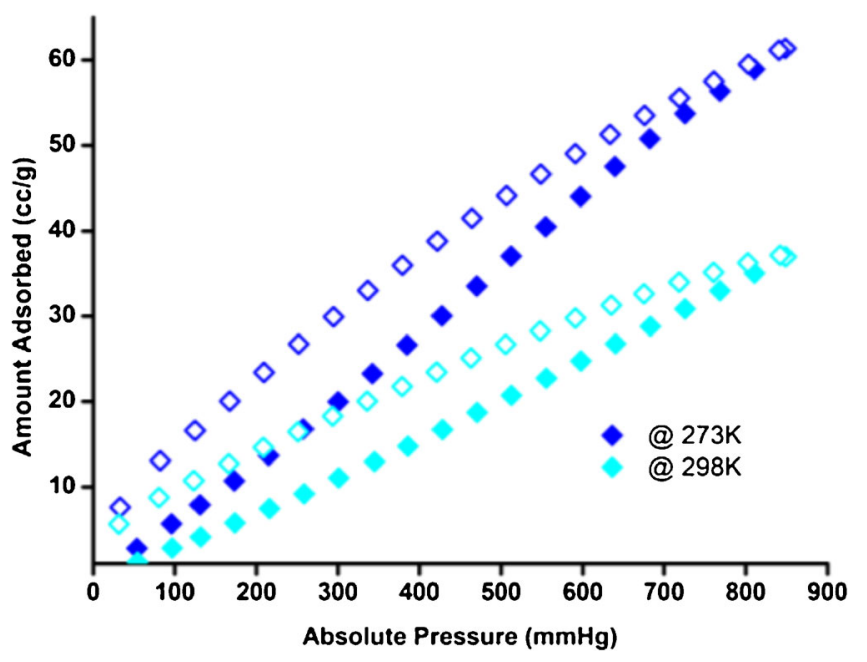

Figure 4. $\mathrm{CO}_{2}$ adsorption carried out on $\mathbf{1}$ at 273 and 298K. Langmuir surface area: $\sim 195 \mathrm{~m}^{2} / \mathrm{g}$. Open squares in all cases represent the desorption. Note $\mathbf{2}$ showed no uptake of $\mathrm{CO}_{2}$ even at $273 \mathrm{~K}$.

We carried out a topological analysis and comparison between $\mathbf{1}$ and $\mathbf{2}$ to identify the source of porosity in $\mathbf{1}$.

Both $\mathbf{1}$ and $\mathbf{2}$ have three-fold interpenetrated diamondoid networks generated from tetrahedral zinc centres coordinated by 4-PyC units. Although, in 2 the interpenetration is more symmetrical and the two independent nets grow from points which are close to the centroid of the adamantane unit of the parent net (nonbonded separation between the three nets has a single value, $8.2149 \AA$ ). We defined the mean planes for each cyclohexane face of the adamantane of $\mathbf{2}$ and the dihedral angles between these planes seem to be relatively symmetrical (figure S2). Whereas, for 1 the independent interpenetrating networks are well shifted from the centroid of the adamantane unit of the parent net and this results in the characteristic two-fold rotational axis of the diamondoid networks ${ }^{4 a}$ not aligning between the interpenetrating nets in $\mathbf{1}$ (figure 5). This is rather unusual three-fold interpenetration. In effect, $\mathbf{1}$ has more of inter-woven networks rather than interpenetrated (figure 3 ). This makes the nets in $\mathbf{1}$ less symmetrical as compared to the ones in $\mathbf{2}$, which seems to make the framework much more open. Also, the dihedral angles associated with the tetrahedrally positioned planes of the adamantane unit of $\mathbf{1}$ are much less symmetrical (figure S2). There is also a non-interpenetrated Zinc isonicotinate metal organic framework reported in the literature. ${ }^{11}$ This has been synthesized under refrigerator temperatures via solvent layering methods. It has a highly symmetrical quartz-type hexagonal framework. However, our extensive attempts to synthesize 

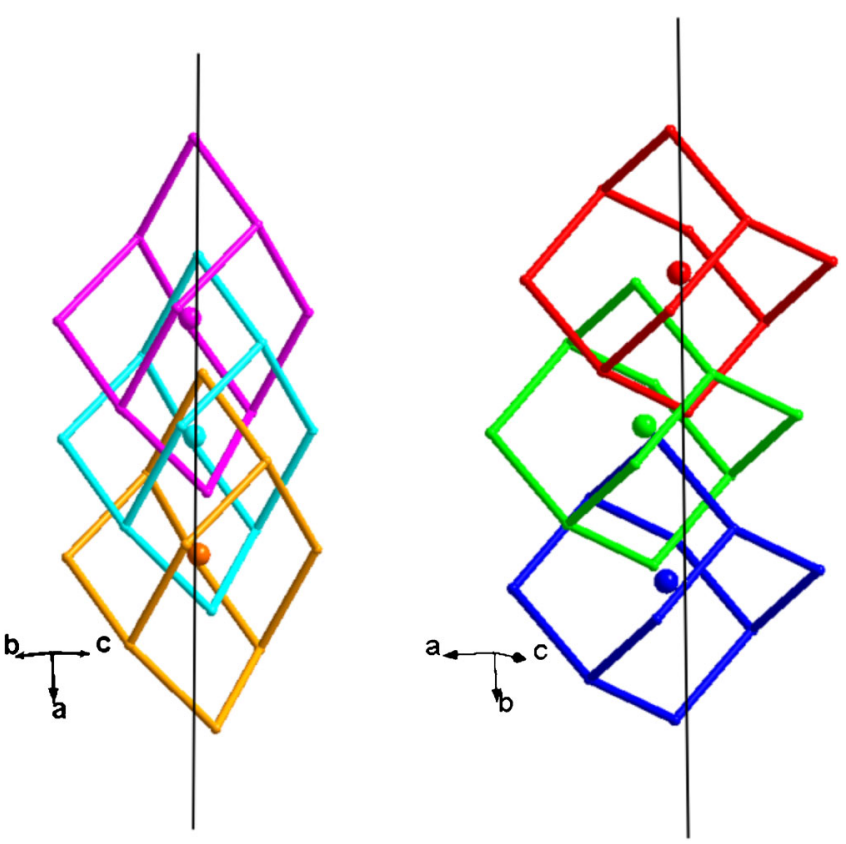

Figure 5. Comparison between the three-fold interpenetration present in $\mathbf{1}$ and $\mathbf{2}$. The black line represents the two-fold axes characteristic of diamondoid networks. Note how the centroids of the adamantane units are aligned in the case of $\mathbf{2}$, but they are substantially shifted in the case of $\mathbf{1}$, making it much more asymmetric interpenetration.

this material with the reported procedure and slightly modified ones have not been successful.

Recently, there has been a surge of interest in demonstrating the use of metal organic frameworks as single source precursors to make carbons with highly dispersed metal or metal oxide nanoparticles. ${ }^{9}$ These carbons are prepared by combusting the metal organic frameworks under oxygen-rich or oxygendeficient streams. There has been reports wherein different porous and non-porous metal organic frameworks have been combusted and the resulting carbon matrix has been shown to be porous. ${ }^{7-9}$ However, these studies have been done on metal organic frameworks which are not essentially related in terms of composition or framework topology. ${ }^{7}$ We realized that, phases 1 and 2 present genuinely related dense and porous frameworks and carrying out these combustion studies on these could be more systematic. Accordingly, we burnt both 1 and 2 at $900^{\circ} \mathrm{C}$ at a rate of $10^{\circ} \mathrm{C} / \mathrm{min}$ under a flow of dry $\mathrm{N}_{2}$. The resulting metal oxide impregnated carbonaceous black powder was characterized via PXRD and SEM to be homogeneous (figure S3 and S4). They were semi-crystalline and have a low angle peak at $2 \theta<2$ characteristic of mesoporous carbons as observed from PXRD (figure $\mathrm{S} 4$ ).

Both $\mathrm{N}_{2}$ adsorption and $\mathrm{CO}_{2}$ adsorption at $77 \mathrm{~K}$ and $273 \mathrm{~K}$ were carried out for the post-combustion compounds (figure 6) (from here on post-combustion phase of $\mathbf{1}$ is denoted $\mathbf{3}$; post-combustion phase of $\mathbf{2}$ is denoted 4). While 3 showed micro (uptake $=10 \mathrm{mmol} / \mathrm{g}$ ) and mesoporous character from $\mathrm{N}_{2}$ adsorption at $77 \mathrm{~K}$ with a total uptake of $20 \mathrm{mmol} / \mathrm{g}$ and a BET surface area of $765 \mathrm{~m}^{2} / \mathrm{g}$ (figure S5), while 4 was practically nonporous. However, both $\mathbf{3}$ and $\mathbf{4}$ showed $\mathrm{CO}_{2}$ uptakes at $273 \mathrm{~K} .3$ has a total $\mathrm{CO}_{2}$ capacity of $\sim 3.5 \mathrm{mmol} / \mathrm{g}$ and 4 has $\sim 1.5 \mathrm{mmol} / \mathrm{g}$ at $273 \mathrm{~K}$. Though 3 and 4 appear extremely homogenous powders under microscopes and SEM (figure S3), their pore size distribution vary over a range indicating a hierarchy of micro and particularly mesopores (figure S6). Thus, these combustion methods might need a lot more optimization to achieve more uniform porosity. From the isotherms it can also been that there is a definite correlation between the porosities of the as-made MOF and the carbon
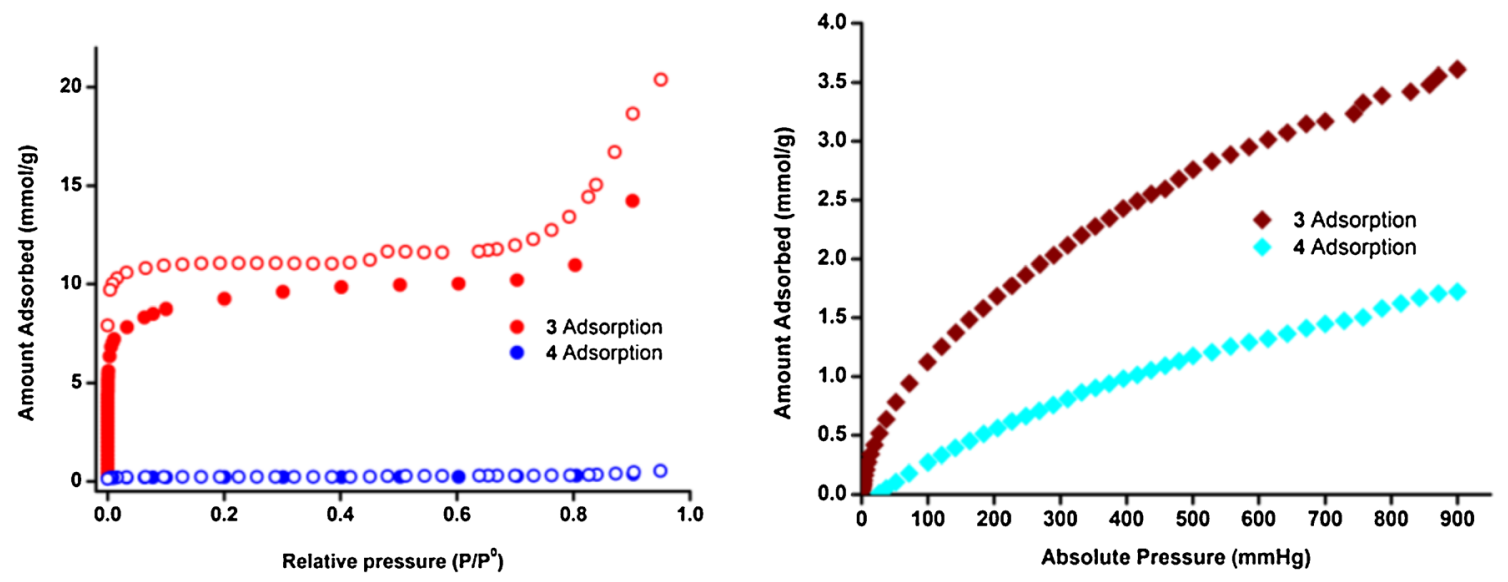

Figure 6. Left: Nitrogen adsorption isotherm of 3 carried out at $77 \mathrm{~K}$. The low pressure region $(\mathrm{P} / \mathrm{Po}=0-$ $0.4)$ indicate a type I isotherm characteristic of microporous behaviour while the high pressure region $(\mathrm{P} / \mathrm{Po}$ $=0.4-1.0$ ) shows a mesoporous behaviour with a typical hysteresis. Right: $\mathrm{CO}_{2}$ isotherms collected at $273 \mathrm{~K}$. The $\mathbf{4}$ generated from denser phase $\mathbf{2}$, is significantly less porous than the one generated from phase $\mathbf{1}$. 
generated from it. 1 with a surface area of $\sim 200 \mathrm{~m}^{2} / \mathrm{g}$ gives a carbon with a surface area $765 \mathrm{~m}^{2} / \mathrm{g}$, while the combustion of $\mathbf{2}$ with almost no porosity generates carbon also with negligible porosity.

Infrared and UV spectra carried out on $\mathbf{1}$ and $\mathbf{3}$ clearly shows expected differences, more importantly the features corresponding to $\mathrm{ZnO}$ can be observed in the spectra of 3 (figures S7-S9) and is quite different from the IR corresponding to the parent phase (figure S8).

\section{Conclusion}

A new interpenetrated but porous zinc isonicotinate metal organic framework has been prepared via systematic investigation of synthetic conditions. The three-fold interpenetration has been compared to the only other known interpenetrated zinc isonicotinate framework. Topological analysis reveals that the interpenetration in $\mathbf{1}$ is less symmetrical, rendering the framework more open. The porosities have been confirmed also from a series of gas adsorption studies. In a separate study, both the dense and the porous three-fold interpenetrated forms of the zinc isonicotinates have been subjected to combustion under nitrogen atmosphere to prepare porous carbon with metal oxide nanoparticles dispersed in them. The resulting black carbon powder is porous when the single source precursor is a porous zinc isonicotinate. Nevertheless, the pore-distribution seems to include micropores and a hierarchy of mesopores, suggesting the need for more optimized combustion to achieve homogenous porosities.

\section{Supplementary Information}

Supporting information includes a pdf document containing various characterization data including PXRD, UV, IR, SEM, BET and pore size distribution and a Table S1 (see www.ias.ac.in/chemsci). And, the crystallographic information file (CCDC: 998824 available free of cost via www.ccdc.cam.ac.uk/data_request/cif).

\section{References}

1. Zhou H-C, Long J R and Yaghi O M 2012 Chem. Rev. 112673

2. Zhang Z, Yao Z-Z, Xiang S and Chen B 2014 Energy Environ. Sci. 72868

3. (a) Lin Z-J, Lü J, Hong M and Cao R 2014 Chem. Soc. Rev. 43 5867; (b) Lu W, Wei Z, Gu Z Y, Liu T-F, Park J, Park J, Tian J, Zhang M, Zhang Q, Gentle III T, Bosch M and Zhou H-C 2014 Chem. Soc. Rev. 43 5561; (c) Mason J A, Veenstra M and Long J R 2014 Chem. Sci. 532

4. (a) Batten S R and Robson R 1998 Angew. Chem. Int. Ed. 37 1460; (b) Carlucci L, Ciani G and Proserpio D M 2003 Coord. Chem. Rev. 246 247; (c) Batten S R 2004 Encyclopedia of Supramolecular Chemistry 735

5. Wells A F 1975 Structural Inorganic Chemistry, $4^{\text {th }}$ edition (London: Oxford University Press)

6. Yuan F, Xie J, Hu H-M, Yuan C-M, Xu B, Yang M-L, Dong F-X and Xue G-L 2013 CrystEngComm. 15 1460

7. Aiyappa H B, Pachfule P, Banerjee R and Kurungot $\mathrm{S}$ 2013 Cryst. Growth Des. 134195

8. (a) Banerjee A, Upadhyay K, Puthusseri D, Vanchiappan A, Srinivasan M and Ogale S B 2014 Nanoscale 6 4387; (b) Banerjee A, Gokhale R, Bhatnagar S, Jog J P, Bhardwaj M, Lefez B, Hannoyer B and Ogale S B 2012 J. Mater. Chem. 2219694

9. Chaikittisilp W, Torad N L, Li C, Imura M, Suzuki N, Ishihara S, Ariga K and Yamauchi Y 2014 Chem. Eur. J. 204217

10. Evans O R, Xiong R-N, Wang Z, Wong G K and Lin W 1999 Angew. Chem. Int. Ed. 38536

11. (a) Wu Y, Li D, Fu F, Tang L, Wang J and Yang X G 2009 J. Coord. Chem. 62 2665; (b) Sun J, Weng L, Zhou Y, Chen J, Chen Z, Liu Z, and Zhao D 2002 Angew. Chem. Int. Ed. 414471

12. (a) Jiang H-L, Makala T A and Zhou H-C 2013 Coord. Chem. Rev. 257 2232; (b) Zhang J J, Wojtas L, Larsen R W, Eddaoudi M and Zaworotko M J $2009 \mathrm{~J}$. Am. Chem. Soc. 13117040

13. (a) He H, Yuan D, Ma H, Sun D, Zhang G and Zhou H-C 2010 Inorg. Chem. 49 7605; (b) Yang G-S, Lang Z-L, Zang H-Y, Lan Y-Q, He W-W, Zhao X-L, Yan L-K, Wang X-L and Su Z-M 2013 Chem. Commun. 49 1088

14. Spek A L 2009 Acta Crystallogr. D 65148 